\title{
PELATIHAN MEMBUAT PREVIZUALIZATION DENGAN ICLONE 6 UNTUK SISWA BERKESULITAN BELAJAR
}

\author{
Julius Andi Nugroho ${ }^{1}$ dan Nuryadi ${ }^{2}$ \\ ${ }^{1}$ Program Studi Desain Komunikasi Visual, Universitas Tarumanagara Jakarta \\ Email:juliusn@fsrd.untar.ac.id \\ ${ }^{2}$ Program Studi Desain Komunikasi Visual, Universitas Tarumanagara Jakarta \\ Email: nuryadi.bayazid@gmail.com
}

\begin{abstract}
ABSTRAK
Kebutuhan sumber daya manusia yang mampu membuat animasi industri film, game dan televisi cukup besar. Para sumber daya manusia ini harus memiliki kreatifitas dan keterampilan dalam menggunakan aplikasi animasi. Salah satu tahapan pra produksi film, game dan program tv yang menggunakan animasi yatiu previsualization. Awalnya previsualization berupa storyboard, seiring perkembangan teknologi digital bertransformasi dalam bentuk $3 D$. FSRD UNTAR bekerjasama dengan Sekolah Talenta dengan memberikan pelatihan pembuatan previsualization kepada siswanya dengan software iClone 6. Hasil pelatihan peseerta mampu membuat sepotong adegan previsualization dengan animasi $3 D$
\end{abstract}

Kata kunci: previsualization, iClone 6, FSRD UNTAR, Sekolah Talenta.

\section{PENDAHULUAN}

Kebutuhan industri film, game dan televisi akan animasi begitu besar, mereka membutuhkan sumber daya manusia yang mumpuni di bidang animasi. Pada acara FAST FEST 2017 para pelaku industri berkumpul dan membicarakan perkembangan industri animasi di Indonesia yang sedang berkembang tetapi tidak dibarengi dengan kebutuhan SDM di bidang animasi. Pemerintah Indonesia sudah berupaya memfasilitasi industri kreatif lewat Perum Produksi Film Negara (PFN) dan Badan Ekonomi Kreatif (BEKRAF), hal ini untuk meningkatkan industri kreatif salah satunya film agar dapat berkontribusi bagi pembangunan. Animasi merupakan subsektor dalam industri kreatif.

Sekolah Talenta merupakan sekolah yang didirikan dengan visi mewujudkan sistem pendidikan bagi Anak Berkesulitan Belajar (ABB) sesuai dengan tujuan pendidikan nasional sehingga $\mathrm{ABB}$ mampu berpartisipasi aktif di tengah masyarakat. ABB merujuk pada istilah learning disabilites yaitu ketidakmampuan belajar dari masalah neurologis bukan kecerdasan seseorang. Ketidakmampuan belajar dapat membuat seseorang kesulitan dalam membaca, menulis, mengeja dan mengerjakan matematika. Kadang dapat juga mempengaruhi kemampuan dalam mengatur, mengingat informasi, mendengarkan, berbicara serta daya ingatan jangka pendek maupun panjang. Orang dengan ketidakmampuan belajar biasanya memiliki kecerdasan rata-rata atau di atas rata-rata (Sinfield, 2017). Siswa Sekolah Talenta sudah menerima penghargaan kompetisi Seni Internasional dari Duta Besar Republik Ceko, ini merupakan apresiasi yang besar bagi siswa Sekolah Talenta. Dari diskusi dengan Tri Yuli Prasetyo, S.Pd Kepala Sekolah Talenta membutuhkan program pembelajaran pembuatan animasi 3D dan previsualization, dan membutuhkan pelatihan animasi untuk memfasilitasi siswa yang minat di animasi. Sekolah Talenta ingin membuka wawasan siswanya di dunia animasi 3D dan previsualization agar siswanya dapat bersaing di industri broadcast, film dan game.

Fakultas Seni Rupa dan Desain Universitas Tarumanagara memiliki materi animasi dan didalamnya ada proyek pembuatan previsualization untuk keperluan pra produksi pembuatan iklan tv atau film. Wawasan ini diperlukan agar lulusan FSRD UNTAR dapat diserap di industri broadcast, film, agency yang memerlukan SDM yang dapat membuat previsualization. Untuk 
membuat sebuah proyek fotografi dan audio visual ada tiga tahapan yaitu; pra produksi, produksi, dan paska produksi. Pada tahapan pra produksi terjadi proses pengembangan konsep menjadi visual lewat storyboard dan ini merupakan bagian dari previsualization. Saat ini di industri mulai mengembangkan storyboard menjadi bentuk animasi 3D, perangkat lunaknya sudah tersedia dan mudah dioperasikan. Sekolah Talenta belum memiliki program pembelajaran pembuatan animasi 3D dan previsualization, dan membutuhkan pelatihan animasi untuk memfasilitasi siswa yang minat di animasi.

Sekolah Talenta dan FSRD UNTAR bekerjasama merancang kegiatan pelatihan animasi yang kedua sebagai kelanjutan dari kegiatan yang pertama yaitu pelatihan animasi 3D dengan iClone 6. Peserta dari Sekolah Talenta sudah mengenal software iClone pada pelatihan pertama dengan mempelajari interface, tools, cara membuat karakter, prop, mengambil karakter dari content manager, basic framing with camera, dan mengatur tata cahaya. Dengan kemampuan dan pengetahuan di atas peserta bisa meningkat ke tahapan pra produksi bahkan produksi, dari previsualization sampai produksi film. Kegiatan pelatihan ini merupakan bagian dari Tri Darma Perguruan Tinggi yaitu pengabdian kepada masyarakat. FSRD UNTAR lewat program studi DKV ingin memberikan materi tentang previzualization kepada peserta dari Sekolah Talenta. Previsualization merupakan bagian dari proses tahapan pra produksi, untuk menampilkan objek virtual digabung dengan video fungsinya visualisasi gambar dari aktor virtual sebagai kepastian bahwa pengambilan gambar sudah baik (Ikeda, Sei. 2008: 952). Previsualization adalah teknik berdasarkan gambar yang dihasilkan komputer untuk memvisualkan adegan, sudut kamera, bloking kamera, tata cahaya, dan situasi, kondisi sebelum pengambilan gambar yang sebenarnya (Ichikari, Ryosuke. 2008: 25). Previsualization ada sebelum era digital dalam bentuk gambar storyboard, pada awal tahun 90 digital previsualization baru dikembangkan (Fink, M. 2003)

\section{METODE PELAKSANAAN PKM}

Metode pelaksanaan pelatihan dilakukan dengan tahapan sebagai berikut: pengumpulan data permasalahan Sekolah Talenta, perancangan pelatihan previz iClone 6, pembuatan modul pelatihan previz dengan software iClone 6 , dan pelaksanaan pelatihan yang dilaksanakan di FSRD UNTAR gedung $K$ lt 5 ruang studio animasi. Acara diawali dengan registrasi dan pembukaan lalu dibagi menjadi dua sesi; sesi pertama pengetahuan tentang previsualization dan animasi karakter dengan mempelajari intro to motion modify, camera navigation, basic keyframing, physic simulation, and character dialogue \& expression. Sesi kedua membuat proyek akhir dengan diberikan script adegan seorang laki-laki dewasa yang sedang berjalan di ruang tamu menuju sofa, kemudian duduk lalu memanggil seseorang. Peserta diharapkan membuat previsualisasi adegan tersebut sambil memperhatikan detail ekspresi karakter, setting ruangan, tata cahaya, dan pergerakan kamera. Adegan tersebut kemudian dirender menjadi format mov.

\section{HASIL DAN PEMBAHASAN}

Pelatihan diadakan hari Kamis 30 November 2017, peserta sudah mendapatkan pengetahuan interface dan tools pada pelatihan sebelumnya sehingga pada pelatihan previzualization mereka langsung diinstruksikan untuk latihan menggerakkan karakter berdasarkan teknik motion modify. Peserta bisa menggerakkan karakter dengan mengikuti path yang sudah dibuat. Peserta juga berhasil membuat mix motion modify atau membuat karakter berjalan dan kepalanya bergerak ke kanan dan kiri. Goal dari pelatihan ini peserta dapat membuat project setup, setting karakter yang ada di template, dan mengatur setting render video. 


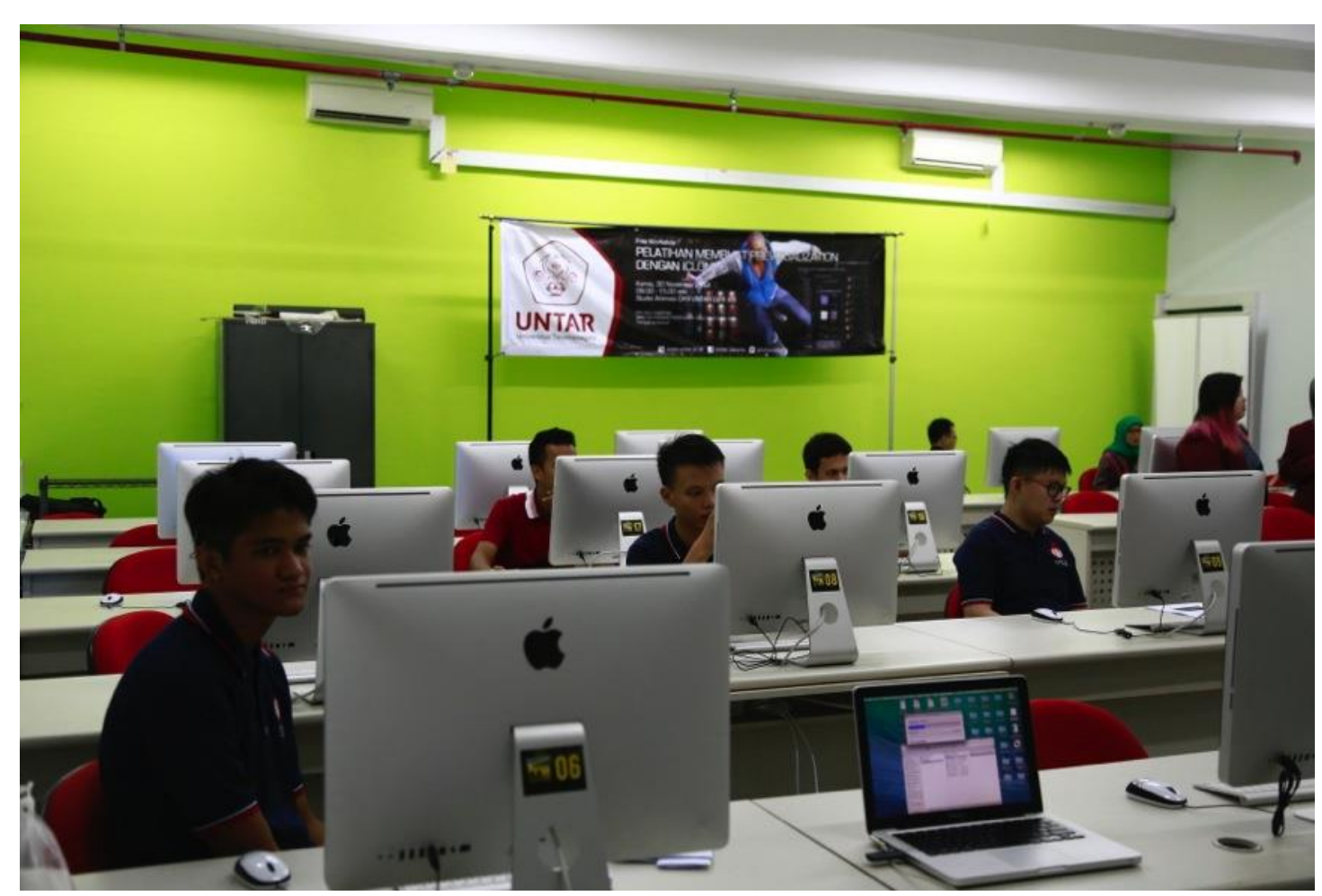

Foto 2. Studio animasi dari FSRD dijadikan tempat pelatihan karena memiliki fasilitas yang cukup memadai.

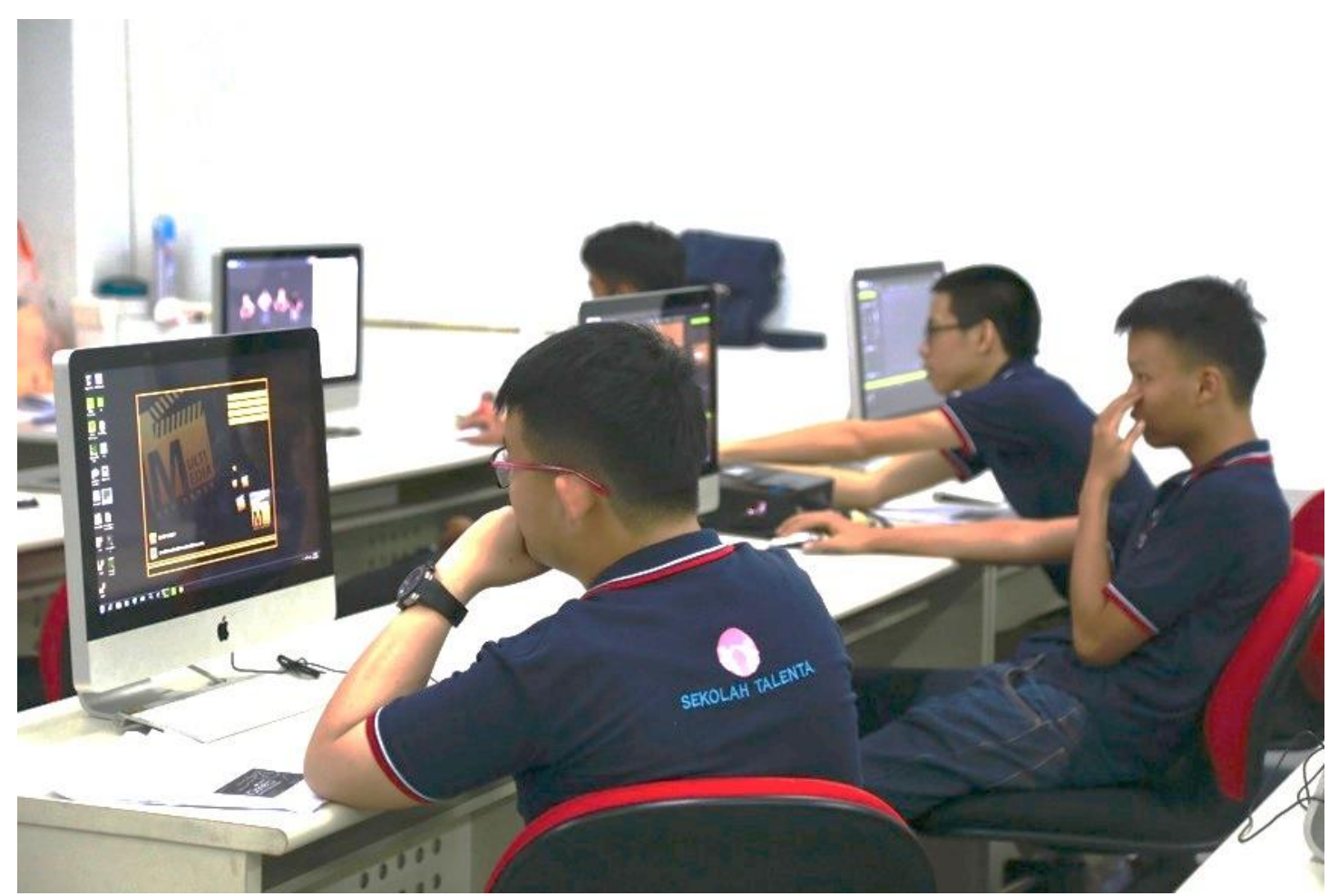

Foto 3. Siswa Talenta memiliki keunikan karena beberapa masuk kategori Anak Berkesulitan Belajar (ABB), tetapi memiliki potensi yang baik dalam intelektual. 


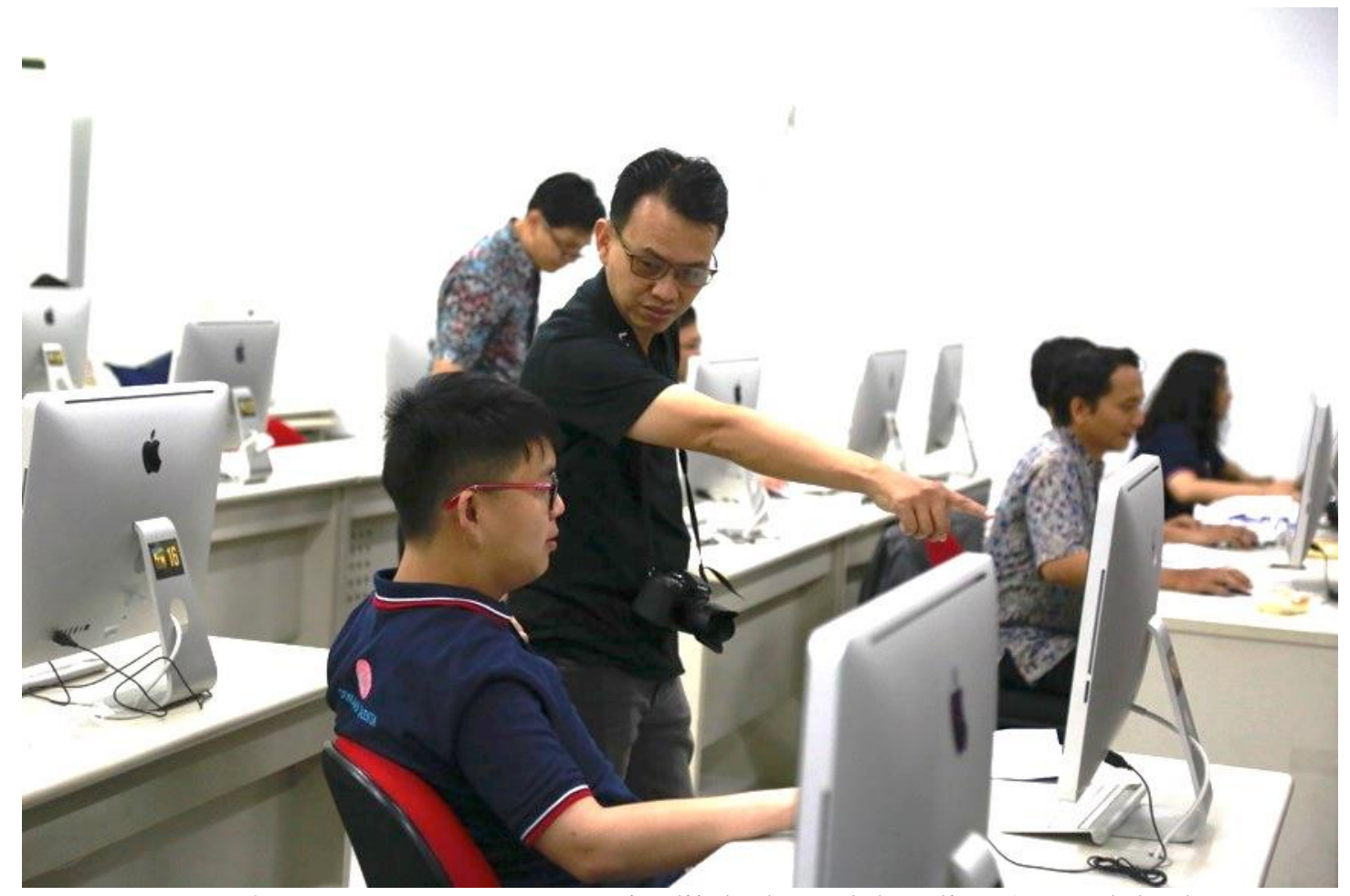

Foto 4. Wawasan tentang previz dijelaskan oleh Julius A.N selaku ketua acara.

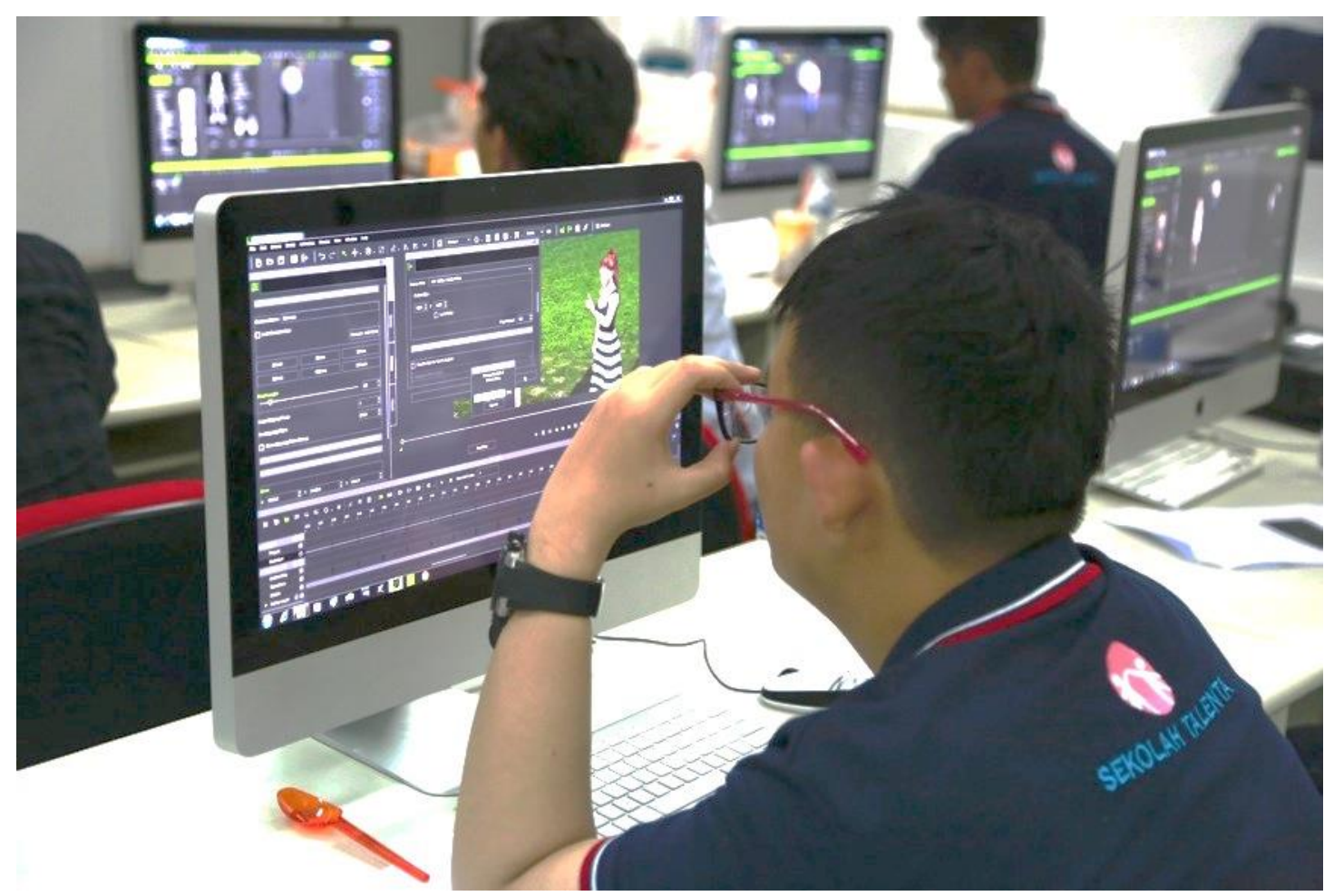

Foto 5. Previz dibutuhkan dalam industri film maupun periklanan sebagai bagian dari tahapan pra produksi. 


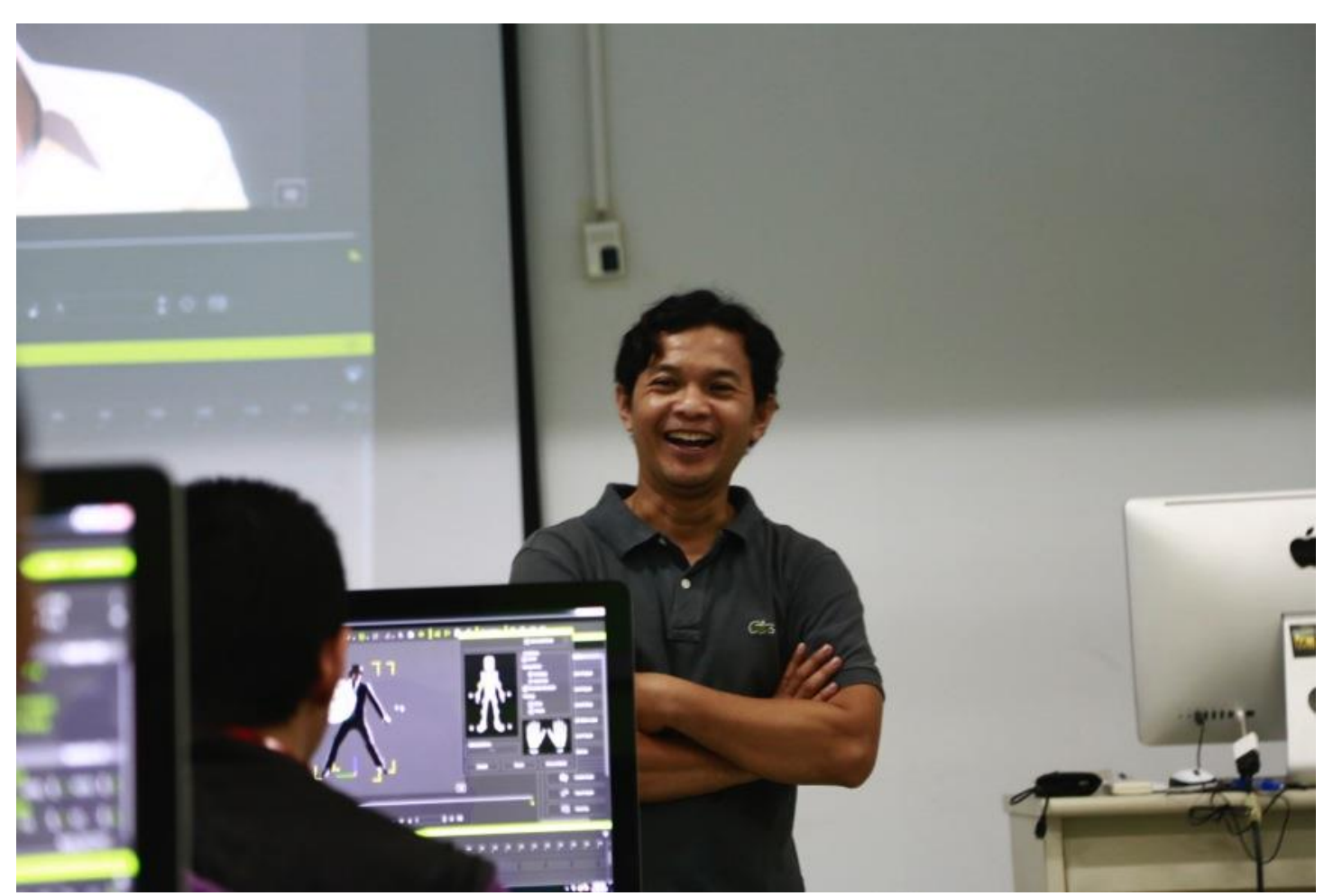

Foto 6. Nuryadi memberikan teknis pembuatan previz dengan software iClone

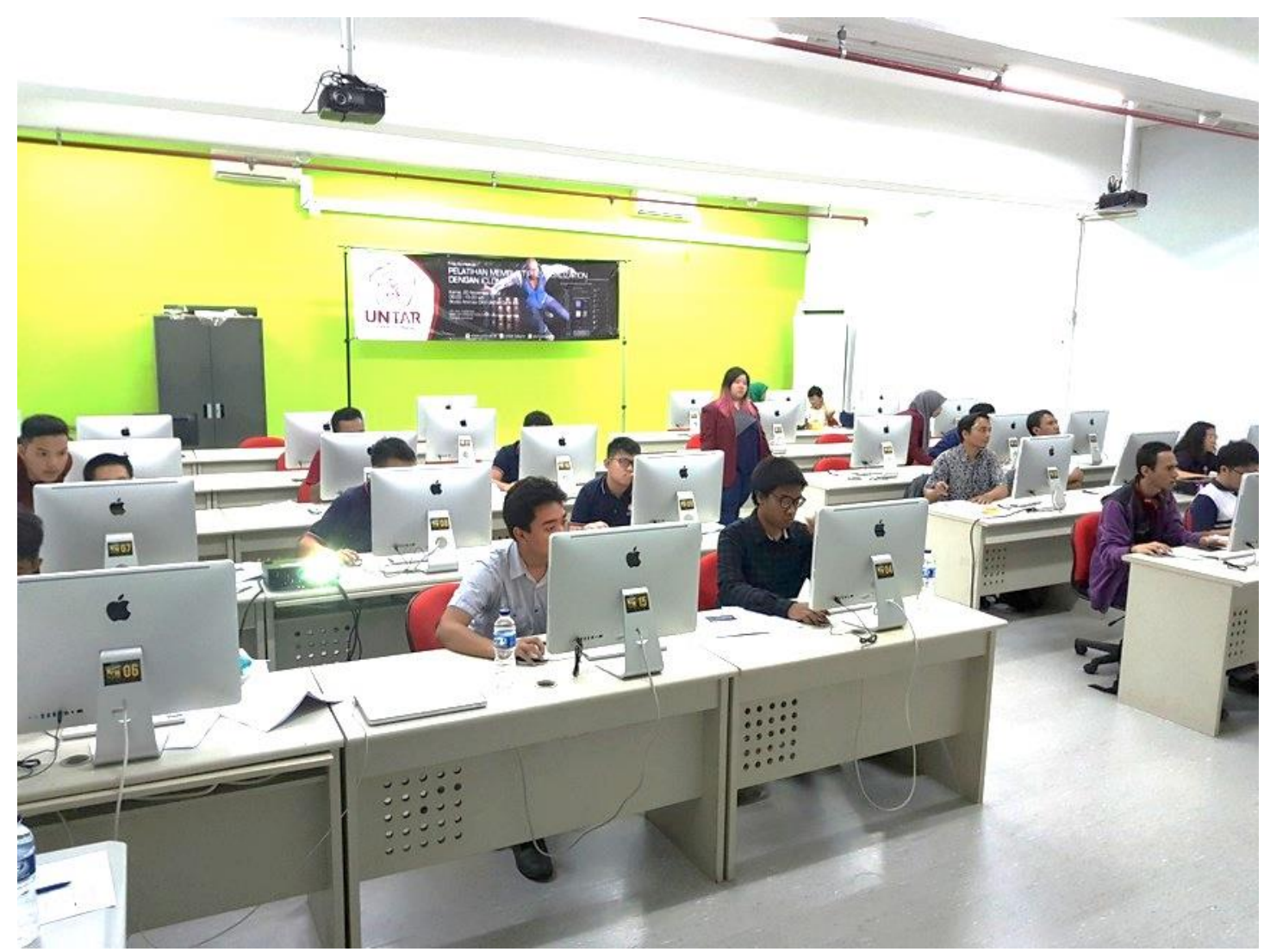

Foto 7. FSRD UNTAR memiliki pengalaman dalam pengajaran pembuatan previz, mahasiswa FSRD UNTAR telah memenangkan kompetisi Asiagraph 2015 di Taiwan. 


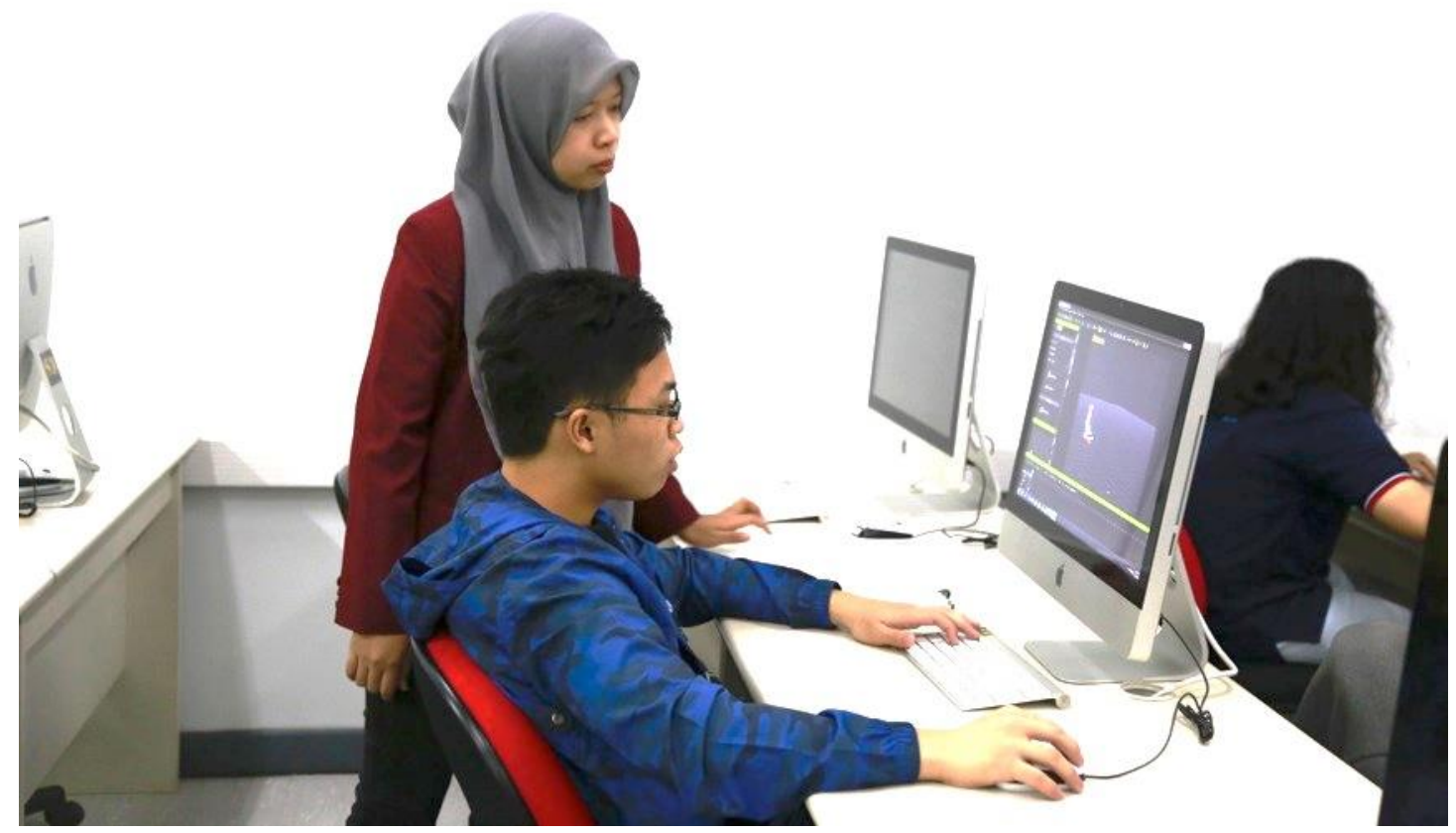

Foto 8. Mahasiswa DKV UNTAR mendampingi peserta dalam pembuatan previz, mereka sudah menguasainya lewat mata kuliah animasi.

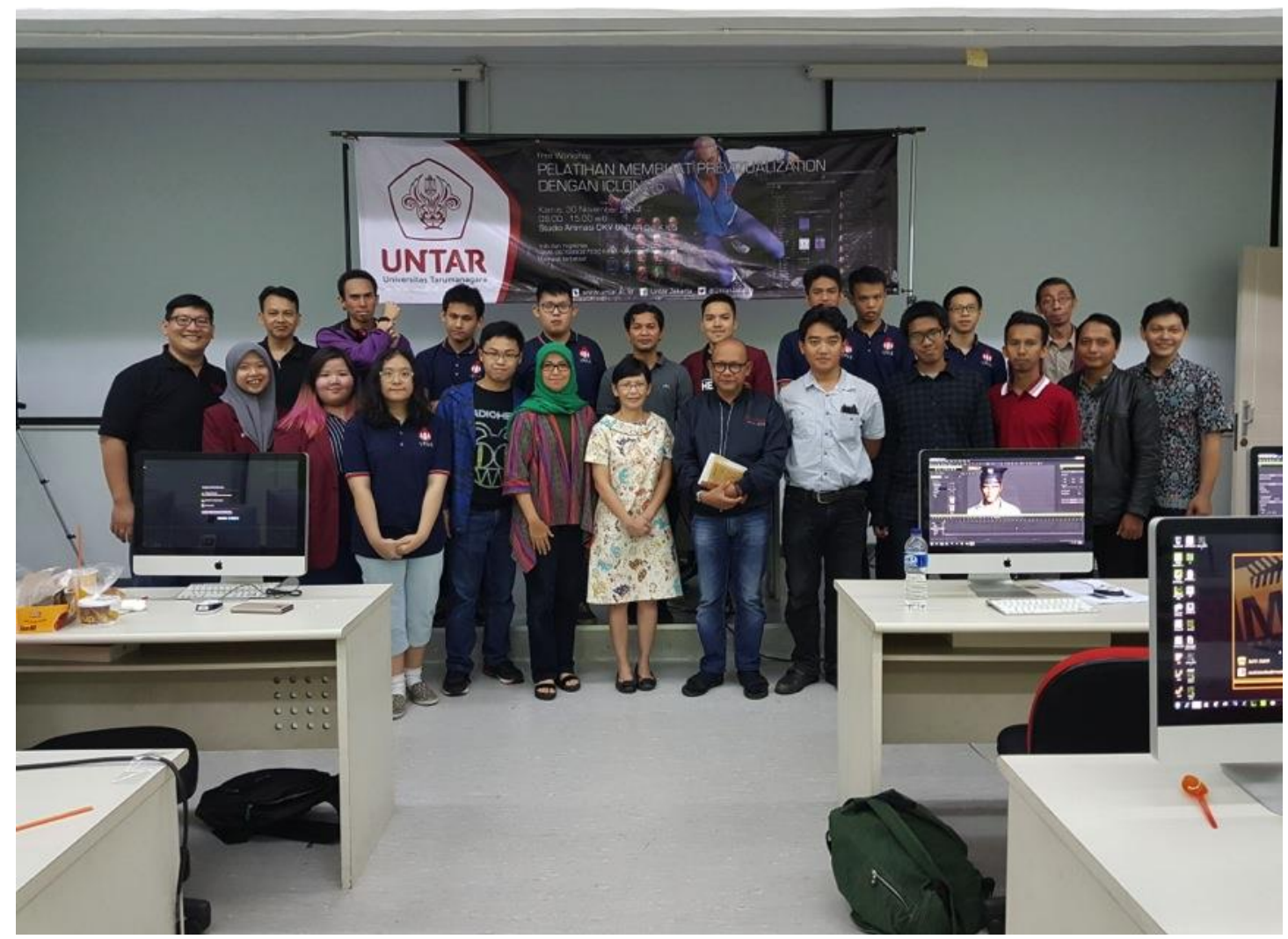

Foto 9. Foto bersama ketua YPAS, Kaprodi DKV UNTAR, tim workshop dan peserta. 


\section{KESIMPULAN DAN SARAN}

Pengetahuan dasar dari software iClone 6 membuat peserta dapat membuat adegan previz dengan baik. Latihan dengan teknik motion modify membuat peserta mampu menggerakkan karakter sesuai dengan path, menambahkan ekspresi wajah karakter, membuat setting latar belakang cerita, mengatur props, tata cahaya untuk luar dan dalam ruang, dan setting render video. Peserta dapat membuat sepotong adegan untuk previs sesuai instruksi yang diberikan. Kelemahan kegiatan ini peserta memerlukan waktu yang lebih lama untuk membuat previs dengan durasi 30 detik. Pelatihan ini diikuti oleh siswa yang masuk kategori Anak Berkesulitan Belajar, salah satunya disebut mengalami Attention Deficit Hyperactivity Disorder (ADHD) atau siswa ini mengalami gangguan peningkatan aktivitas motorik yang berlebihan, terlihat saat pelatihan ada siswa yang gelisah dan tidak bisa duduk tenang. Beruangkali menanyakan kapan pelatihan selesai atau ijin ke kamar kecil berkali-kali. Tetapi siswa ini dapat menyelesaikan project yang diberikan saat pelatihan dengan baik.

\section{Acknowledgement}

Kegiatan ini didanai oleh DPPKM UNTAR dan atas terlaksananya kegiatan PKM ini, kami berterima kasih kepada Jap Tji Beng, PhD direktur PPKM UNTAR, Kurnia Setiawan, S.Sn., M.Hum. dekan FSRD UNTAR yang mendukung kegiatan ini. Juga terima kasih kepada Arini Soewarno ketua YPAC, dan Tri Yuli Prasetyo, S.Pd. Buat mahasiswa kami, Yohannes, Jessica Rien dan Silvi Salsabil yang telah membantu pelaksanaan PKM.

\section{REFERENSI}

Previsualization (previs) adalah bagian dari tahapan pra produksi baik dalam film live action maupun animasi. Awalnya previs berupa storyboard yang dibuat tahun 1920 untuk film animasi Stemaboat Willie kemudian storyboard menjadi standar dalam pembuatan film untuk memvisualkan filmnya sebelm proses produksi (Lemon, 2012). Michael Fink seorang visual efek Holywood memiliki pengalaman panjang sebelum dunia digital. Ia membuat previsualization mulai dari storyboard yang digambar tangan ke dalam video atau film. Diakhir tahun 80, presentasi previsualization menggunakan lipstick video camera tetapi memiliki kelemahan pada lensa yang tidak sesuai dengan lensa kamera film. Di awal tahun 90 digital previsualization menjadi kenyataan (Fink, 2003). Pengenalan citra yang dihasilkan komputer rendering 3D oleh Lynda Weinman untuk film Star Trek V. Penggunaan aplikasi grafik 3D atau perangkat lunak previsualization dikenal sebagai digital previsualization atau $3 D$ previsualization (Lindsay, 2013). Keuntungan menggunakan previsualization sebagai berikut; mengatasi masalah pada pacing, timing, dan continuity, membantu dalam menentukan sudut pengambilan gambar dan framing, mengidentifikasi kebutuhan props dan assets, mengatasi masalah pada modelling dan rigging, lebih efektif dan efisien dalam komunikasi dibandingkan dengan gambar storyboard, mempermudah dan mempercepat pekerjaan animator, meningkatkan kualitas film yang diproduksi, software previs dalpat mengambil alih istilah penamaan dalam alur kerja produksi, dan memudahkan pemberian feedback dan revisi pada proses pra produksi (Harvey. 2010)

Fink, M. 2003, A Little History on Previsualization, Animation World Network, http://www.awn.com/articles/production/little-history-previsualization, diakses 1 Agustus 2017

Harvey, Louise. (2010). Designing Efficiency: The Benefits of Previsualisation in Film and 
Animation Teaching Programs. https://core.ac.uk/download/pdf/143860629.pdf. diakses 1 Agustus 2017.

Lemon, Nicole. (2012). Previsualization in Computer Animated Filmmaking. Thesis from The Ohio State University.

https://etd.ohiolink.edu/rws_etd/document/get/osu1345569188/inline, diakses 1 Agustus 2017

Lindsay, Clifford. (2013). Programmable Image-Based Light Capture for Previsualization. Dissertation from Worcester Polytechnic Institute. https://web.wpi.edu/Pubs/ETD/Available/etd-040213-

115728/unrestricted/clindsay_dissertation_final_etd_.pdf, diakses 1 Agustus 2017.

S. Ikeda et al., "Real-time outdoor pre-visualization method for videographers - real-time geometric registration using point-based model_, " 2008 IEEE International Conference on Multimedia and Expo, Hannover, 2008, pp. 949-952.

Sinfield, Jacqueline. (2017). The Relationship Between ADHD and Learning Disabilities. https://www.verywellmind.com/is-adhd-a-learning-disability-4116126, diakses 1 Agustus 2018. 